\title{
Primary Outcome Measure
}

National Cancer Institute

\section{Source}

National Cancer Institute. Primary Outcome Measure. NCI Thesaurus. Code C98772.

The primary measurement(s) or observation(s) used to measure the effect of experimental variables in a study, or for observational studies, to describe patterns of diseases or traits or associations with exposures, risk factors or treatment. These are the outcome measures used to assess the primary objective(s). 